\title{
Characterization on Contacting Surfaces of MEMS Electrostatic Switches by SEM, EDXA, and XPS
}

\author{
I. A. Afinogenov, ${ }^{1}$ I. A. Zeltser, ${ }^{2}$ E. B. Trunin, ${ }^{2}$ and A. Tolstoguzov ${ }^{3,4}$ \\ ${ }^{1}$ Special Engineering Design Bureau Joint Stock Company (SEDB JSC), Nekhinskaya 55, 173000 Veliky Novgorod, Russia \\ ${ }^{2}$ Ryazan Metal Ceramics Instrumentation Plant Joint Stock Company (RMCIP JSC), Novaya 51B, 390027 Ryazan, Russia \\ ${ }^{3}$ Department of Industrial Electronics, Ryazan State Radio Engineering University (RSREU), Gagarin 59/1, 390005 Ryazan, Russia \\ ${ }^{4}$ Centre for Physics and Technological Research (CEFITEC), Departamento de Física da Faculdade de Ciências e Tecnologia (FCT), \\ Universidade Nova de Lisboa, 2829-516 Caparica, Portugal
}

Correspondence should be addressed to A. Tolstoguzov; a.tolstoguzov@fct.unl.pt

Received 17 December 2014; Accepted 23 February 2015

Academic Editor: Francesco Delogu

Copyright (C) 2015 I. A. Afinogenov et al. This is an open access article distributed under the Creative Commons Attribution License, which permits unrestricted use, distribution, and reproduction in any medium, provided the original work is properly cited.

\begin{abstract}
We focus on the origin and sources of surface contamination and defects causing the failure of MEMS electrostatic switches. The morphology, and elemental and chemical compositions of the contacting surfaces, conducting paths, and other parts of switches have been characterized by means of SEM, EDXA, and XPS in order to understand the difference between the data collected for the devices that had passed the electrical conductivity test and those found to be defective. $\mathrm{C}, \mathrm{O}, \mathrm{Al}, \mathrm{Ca}, \mathrm{Ti}, \mathrm{Cu}$, and some other impurities were detected on the details of defective switches. Contrariwise, the working switches were found to be clean, at least on the level of EDXA and XPS sensitivity. The main sources of surface contamination and defects were incompletely deleted sacrificial layers, substrate materials, and electrolytes employed for Rh plating of the contacts. The negative influence of foreign microparticles, especially alumina and copper oxides, on the conductivity and porosity of contacts was highlighted.
\end{abstract}

\section{Introduction}

The performance and reliability of microelectromechanical systems (MEMS) depend critically on the ability of the contacting surfaces to remain as conductive as possible. Surface contamination is a known cause of MEMS switches failure due to retarding of current flow [1]. They have different origin. Some can be native to the surface, such as oxides or hydroxides; others can appear during manufacturing operation, such as adsorbed impurities and various mechanical micro- and nanoparticles. Microstructural features, especially porosity, have a great impact on the switching reliability too.

In our previous works [2-4], we showed that contamination and defects of the contacting surfaces of reed switches affected their conductivity and breakdown voltage. Reed switches belong to the class of electromechanical devices of millimeter dimension. Since the contact area of MEMS switches is considerably smaller, an impact of surface contamination and defects on the electrical parameters is greater than that in case of reed switches.

The present work is a continuation and further development of our previous research: using scanning electron microscopy (SEM), energy dispersive X-ray analysis (EDXA), and X-ray photoelectron spectroscopy (XPS) we have studied morphology and elemental and chemical compositions of MEMS electrostatic switches. The data collected for devices that had passed the electrical conductivity test and for defective ones are compared, and the factors causing the degradation of conductivity are analyzed and discussed in the terms of improving technological cycle of MEMS production.

\section{Materials and Methods}

We studied two MEMS electrostatic switches manufactured at SEDB JSC (Veliky Novgorod, Russian Federation). One of them successfully passed the electrical conductivity test 


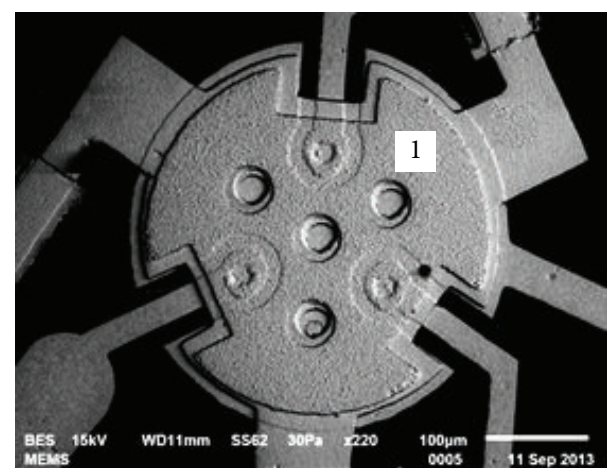

(a)

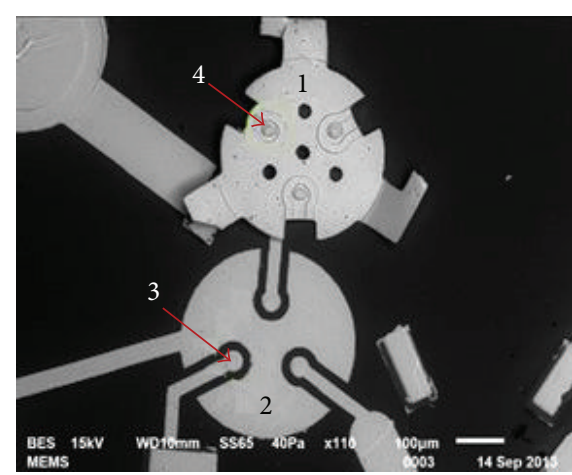

(b)

FIGURE 1: SEM images of an electrostatic MEMS switch: (a) an assembled device without hermetic housing, (b) movable cover (1) and fixed base (2). In the panel (b) the movable part was bent back prior to analysis; numbers (3) and (4) are marked contacts on the fixed and movable parts, respectively.
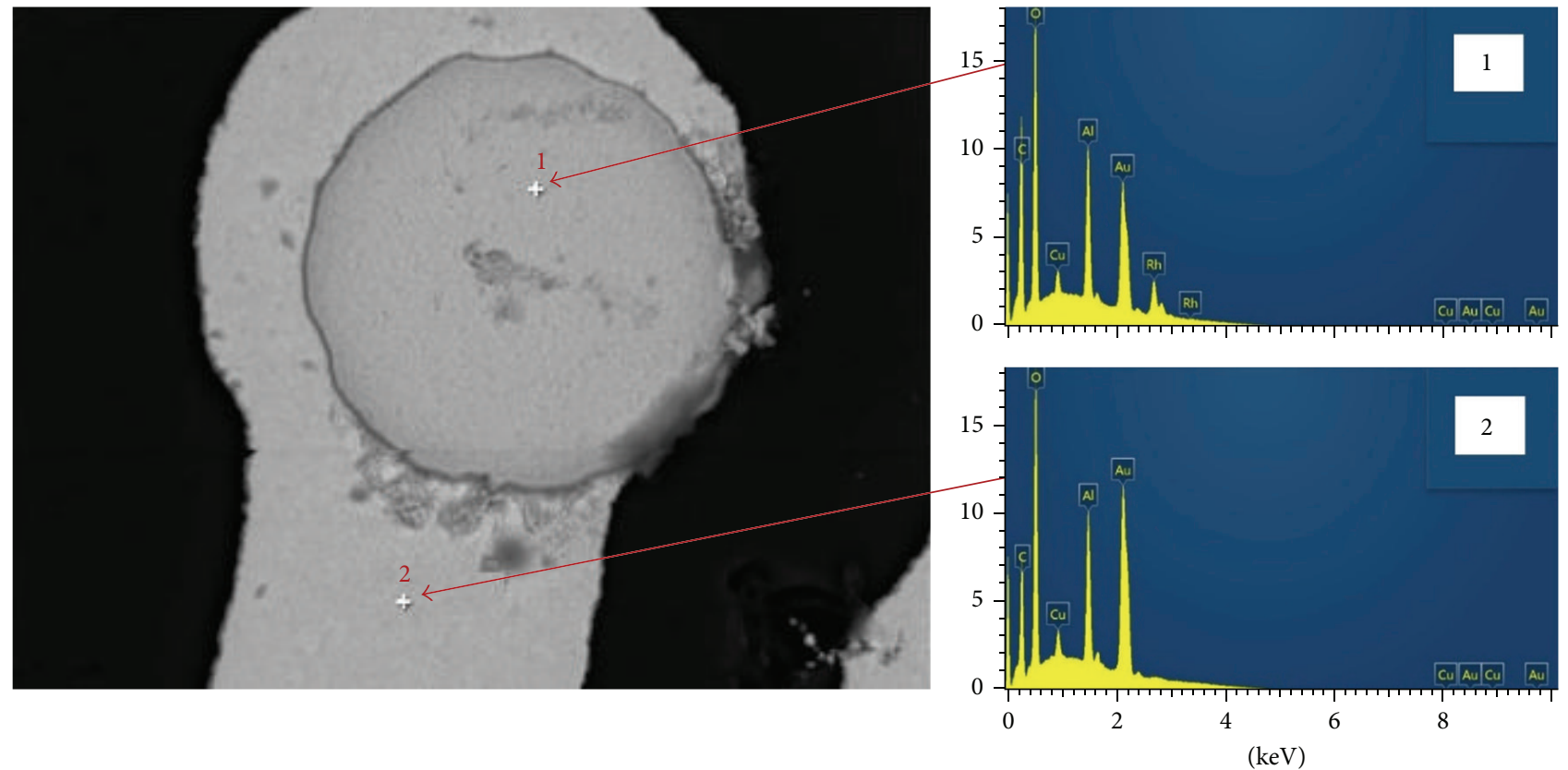

FIGURE 2: SEM image $(\times 2200)$ and EDX analysis of the fixed base of DS switch. The elemental composition (wt.\%) in point (1) on the contacting surface (marked in Figure 1(b) by \#3) is Au 52.6, Rh 24.5, O 12.3, Al 8.4, and $\mathrm{Cu} 2.2$, and in point (2) on the conducting path-Au 77.9, $\mathrm{O} 11.4$, $\mathrm{Al}$ 8.4, and $\mathrm{Cu} 2.3$.

$\left(R_{\mathrm{st}} \leq 0.15 \mathrm{Ohm}\right)$; the other was found to be defective $\left(R_{\mathrm{st}}>\right.$ $0.15 \mathrm{Ohm})$. Hereafter, in this paper, the first switch will be referred to as working sample (WS) and the second one as defective sample (DS).

MEMS electrostatic switch (without hermetic housing) and its constituent parts are shown in Figure 1. The device was assembled on one- or double-faced polished sapphire substrate. At the first stage, technological holes of 50-100 $\mu \mathrm{m}$ in diameter were made by laser with following chemical treatment. At the second stage, these holes were covered by copper by means of electrolytic deposition during ca. 40 hours. Thermovacuum deposition of gold was used for fabrication of the signal line and control elements. Two gold layers produced via successive thermovacuum and electrolytic deposition coated the mechanically movable cover, which forms the console of electrostatic attenuator. The thin layer of rhodium was chemically deposited on the surface of contacts for improving their wear properties. Sacrificial layer provides the spacing in the contact assembly in the range of 3-5 $\mu \mathrm{m}$ depending on the modification of the devices. At the final stage, this layer was removed using liquid chemical etching with following twophase drying to prevent adhesion of the contacts induced by capillary forces.

Microstructural information was collected using a JEOL JSM-6610LV (Japan). An energy dispersive X-ray microanalyzer INCA X-MAX by Oxford Instruments (England) allowed determining quantitative elemental composition of the samples over an area of $1-5 \mu \mathrm{m}$ in diameter. Chemical 

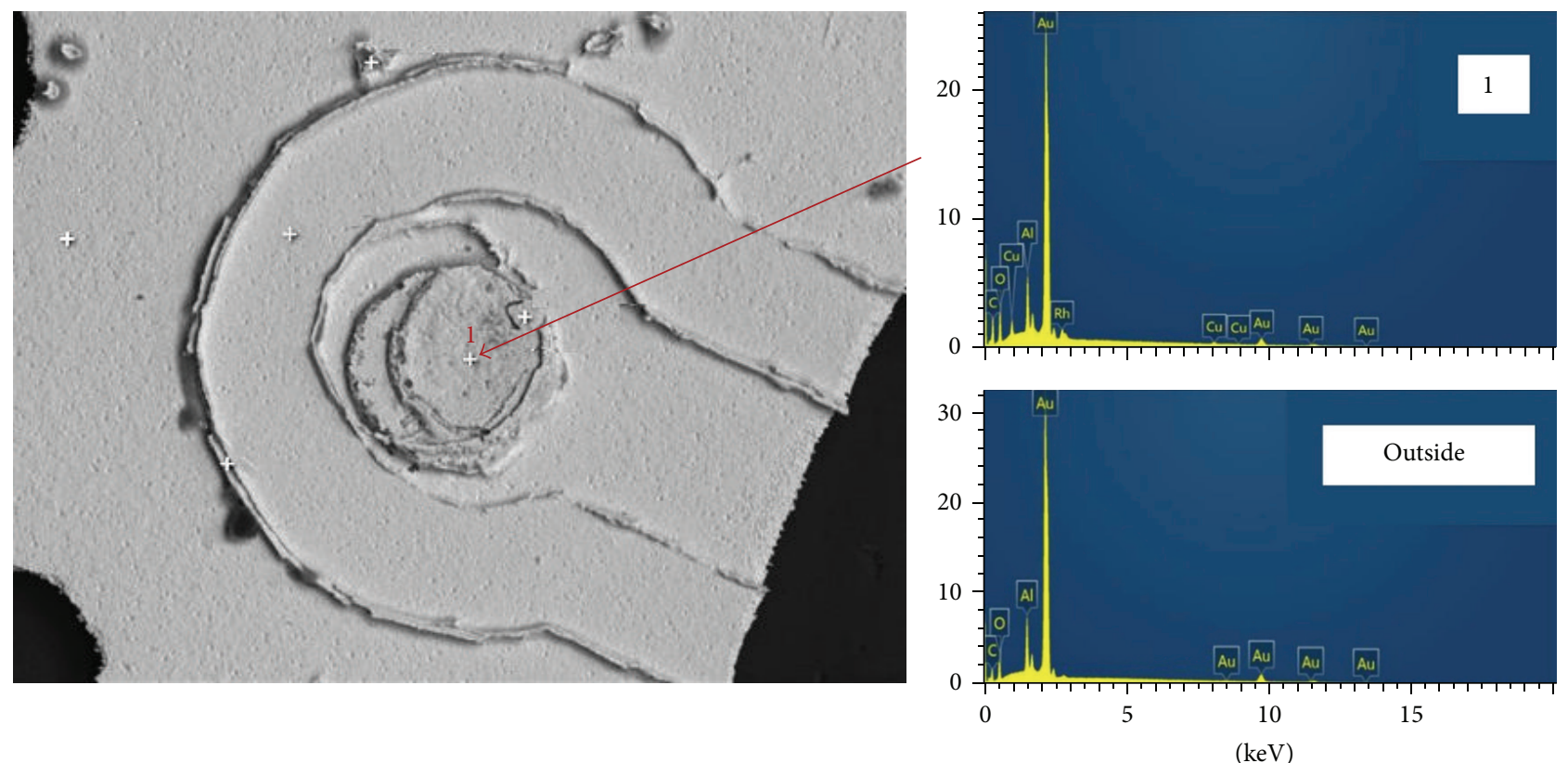

FIGURE 3: SEM image ( $\times 1100)$ and EDX analysis of the movable cover of DS switch and its reverse side. The elemental composition (wt.\%) in point (1) on the contacting surface (marked in Figure 1(b) by \#4) is Au 82.8, O 7.4, Al 3.8, Cu 3.2, and Rh 2.8, and in the outside-Au 88.7, O 7.0, and $\mathrm{Al} 4.3$.

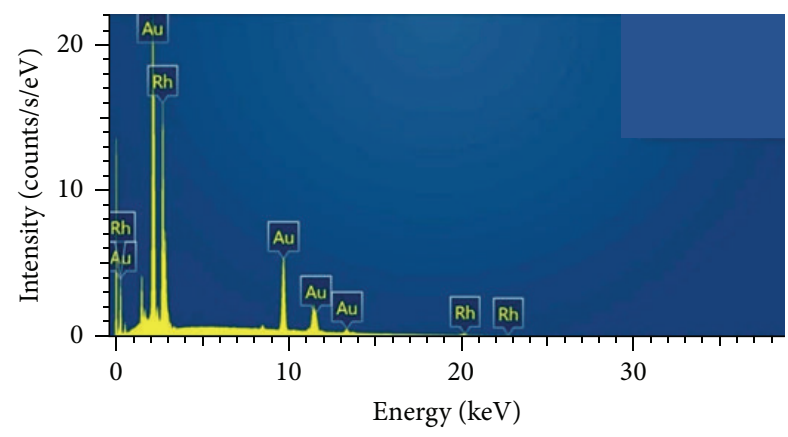

FIGURE 4: EDXA spectrum of the contacting surface of WS switch. The elemental composition (wt.\%) is Au 54.7 and $\mathrm{Rh} 45.3$.

analysis of near-surface layers was carried out with a scanning X-ray photoelectron spectrometer Quantera SXM by Physical Electronics (USA). The measurements were performed in an ultra-high vacuum of $10^{-8} \mathrm{~Pa}$ without preliminary sputter cleaning of the contacting surfaces. We used an Al $\mathrm{K} \alpha$ $1486.6 \mathrm{eV}$ X-ray beam of $7 \mu \mathrm{m}$ in diameter.

\section{Results and Discussion}

3.1. SEM and EDX Analysis. The results of measurements carried out in the different points of DS switch are shown in Figure 2 (for the fixed base) and Figure 3 (for the movable cover). Besides main components ( $\mathrm{Au}$ and $\mathrm{Rh}$ ), various surface impurities like $\mathrm{C}, \mathrm{O}, \mathrm{Al}$, and $\mathrm{Cu}$ were detected.

About nature and sources of these impurities. Carbon mainly originates from organic solvents used in technological operations for cleaning and degreasing of details. In

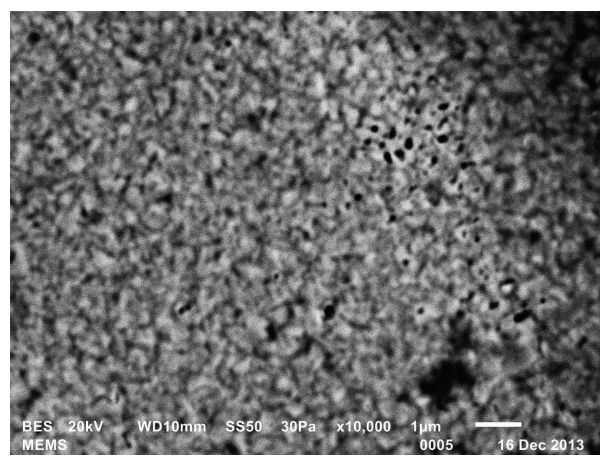

FIGURE 5: Enlarged SEM image $(\times 10000)$ collected around the point $\# 1$ on the contacting surface of the fixed base of DS switch (see Figure 2).

addition, it enters into the composition of different gaseous compounds (hydrocarbons, oxides, etc.) adsorbing on the contacting surfaces from ambient air. During switching cycles, these adsorbed species can form nonconducting films via mechanoelectrical polymerization. Oxygen is a component of organic contamination and oxides. The most probable sources of alumina and copper oxides are sacrificial layer and substrate materials. Both hydrocarbon films and oxide microparticles are able to retard current flow and reduce the resource and stability of MEMS switches. It should be noted that no impurities were found on the contacting surfaces of WS switch, only $\mathrm{Au}$ and $\mathrm{Rh}$ with approximately equal concentration and without any traces of sacrificial layer or substrate materials (Figure 4).

Other source of oxides is gold and rhodium electrolytes, where disperse oxide particles can be in suspension. It is 

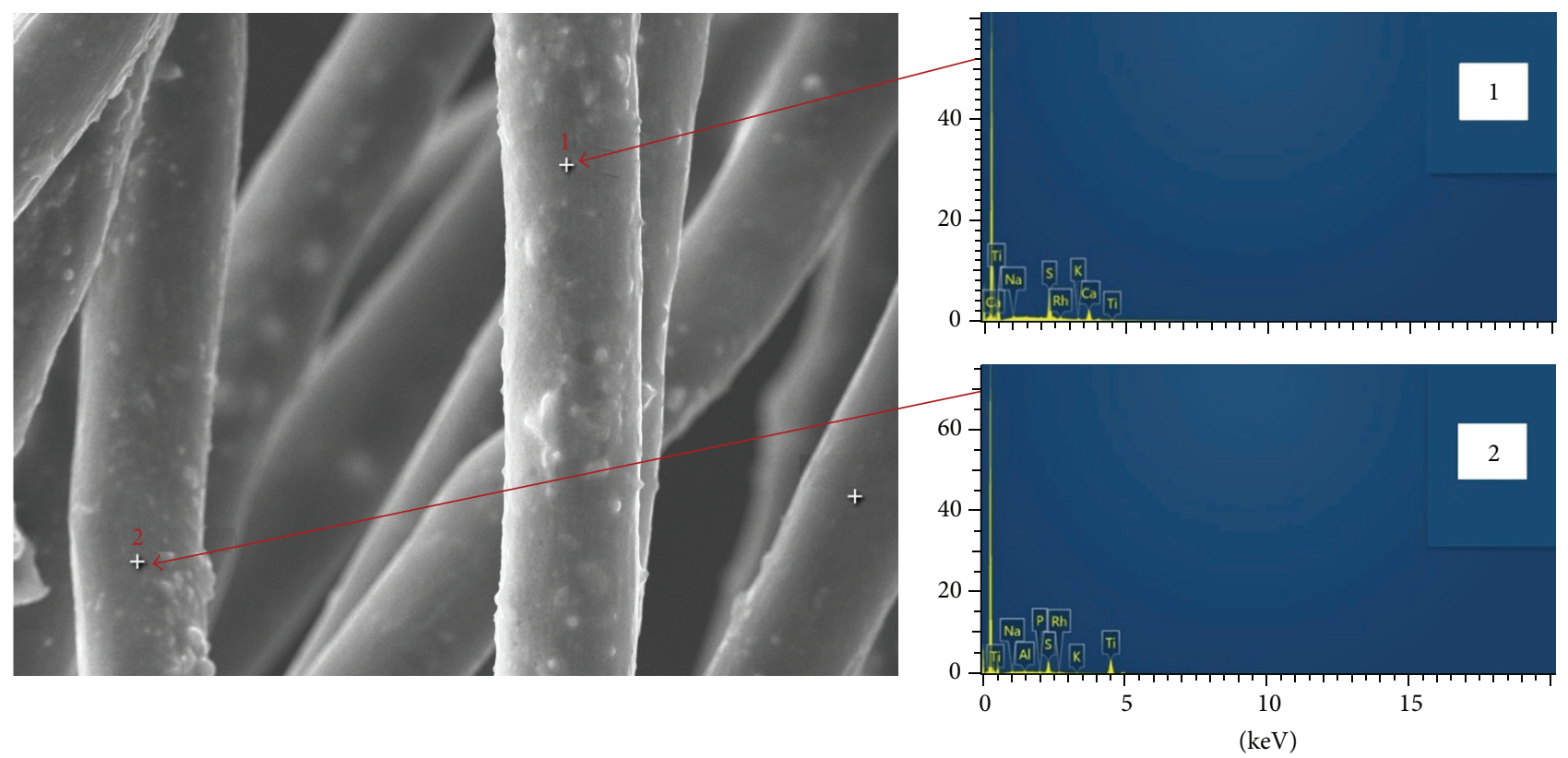

Figure 6: SEM image ( $\times 1100)$ and EDX analysis of an ashless filter used for the filtration of Rh electrolyte. The elemental composition (wt.\%) in point (1) is S 45.8, Ca 34.4, Rh 10.5, Na 4.2, K 3.5, and Ti 1.6, and in point (2)-Ti 63.9, S 21.3, Rh 6.3, Na 3.6, P 1.7, Al 1.6, and K 1.6.

shown [5] that such microparticles have caused the porosity of electrolytic coatings on the contacting surfaces of reed switches that increases their resistivity. The concentration of defects depends on the thickness of coatings, the diameter of particles, and their size distribution. With decreasing thickness of the coatings, smaller particles play more crucial role in the distortion of structural integrity. That stimulates increasing of the density of defects and adsorption capacity of surface and results in increasing of the contact resistivity.

Microstructure of the contacting surface around point \#1 on the fixed base of defective switch is shown in Figure 5. Black points are pores of the lateral sizes in the range of 0.1$1 \mu \mathrm{m}$. The area of EDX analysis, that is, $1 \mu \mathrm{m}$ in diameter, includes one or a few pores. The elemental composition (wt.\%) in this area (point \#1 in Figure 2) is Au 52.6, Rh 24.5, $\mathrm{O} 12.3, \mathrm{Al}$ 8.4, and $\mathrm{Cu} 2.2$ (see Figure 2). Very likely is the fact that aluminum and copper (along with oxygen) relate to oxides microparticles forming these pores.

Electrolytes used for plating of the contacts can contain foreign microparticles as well. To confirm that, we carried out SEM and EDX analysis of an ashless filter used for the filtration of Rh electrolyte. The results are shown in Figure 6. SEM image demonstrates the presence of the particles sized over the range of tenths to a few micrometers. Their elemental composition includes alkaline metals, $\mathrm{S}, \mathrm{P}, \mathrm{Ca}, \mathrm{Al}$, and $\mathrm{Ti}$. These impurities, especially different compounds containing $\mathrm{Ca}, \mathrm{Al}$, and $\mathrm{Ti}$, affect the conductivity of MEMS contacts.

3.2. XPS Analysis. X-ray photoelectron spectroscopy was used for studying surface chemical composition of the samples. Chemical mappings collected for the fixed base of DS switch are shown in Figure 7. The images represent the lateral distributions of $\mathrm{Au} 4 \mathrm{f}((\mathrm{a}),(\mathrm{b})), \mathrm{Rh} 3 \mathrm{~d}(\mathrm{~b})$, and $\mathrm{Cu} 2 \mathrm{p}$ (c) peak intensities. The size of each image is $210 \times 210 \mu \mathrm{m}^{2}$. In points P1-3 and P5 shown in Figure 7(a), we measured XPS survey spectra. The area of analysis was $27 \mu \mathrm{m}$ in diameter for points P1-3 and $110 \mu \mathrm{m}$ for P5 that includes the contacting surfaces plated by rhodium.

The XPS spectra are presented in Figure 8. In point P5 (Figure 8(a)) the intense peaks of $\mathrm{Au}, \mathrm{O}, \mathrm{Al}$, and $\mathrm{C}$ were observed. The $\mathrm{Al}$ and partly $\mathrm{O}$ signals originate from substrate material and surface contamination like $\mathrm{Al}_{2} \mathrm{O}_{3}$. Faint peak of rhodium was identified. As for ruthenium, its main peak $\mathrm{Ru} 3 \mathrm{~d}$ was overlapped by the intense peak of carbon $\mathrm{C} 1 \mathrm{~s}$. We are not fully confident in the presence of $\mathrm{Ru}$ in the sample in spite of the fact that the peak near the binding energy (BE) of $460 \mathrm{eV}$ can be attributed to $\mathrm{Ru} 3 \mathrm{p}_{3 / 2}$. The peaks of tin and iodine relate to the previous measurements of $\mathrm{SnI}_{4}$ (memory effect). Also the peaks of $\mathrm{Cu}, \mathrm{Cr}, \mathrm{N}$, and probably Ni were observed. The peak at $\mathrm{BE}=684 \mathrm{eV}$ can be attributed to F 1s. However, its intensity is small. Satellites of the intense $\mathrm{C}$ 1s and $\mathrm{O}$ 1s peaks appeared due to employing of nonmonochromatic X-ray probing beam.

The XPS spectra measured for points P1-P3 are presented in Figure 8(b). These spectra are noisier as compared with the spectrum for P5 due to the smaller area of analysis. Since the relative contribution of $\mathrm{Rh}$-covered contacts is bigger, the peaks of rhodium are more intense than those in case of P5 area (Figure $8(\mathrm{a})$ ). The intensity of $\mathrm{Cu} 2 \mathrm{p}$ peak is approximately the same for every XPS spectrum. It means that copper impurity is uniformly distributed on the contacting surface. The $\mathrm{Cu} 2 \mathrm{p}$ mapping shown in Figure $7(\mathrm{c})$ confirms this conclusion. At the same time, no copper, aluminum, and oxygen peaks were observed on the contacting surfaces of WS switch. 


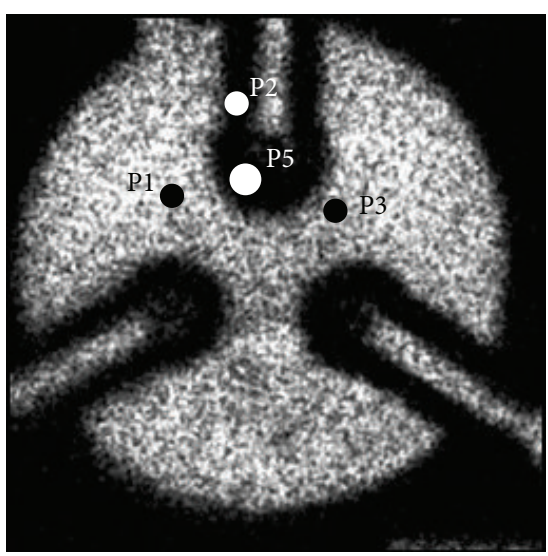

(a)

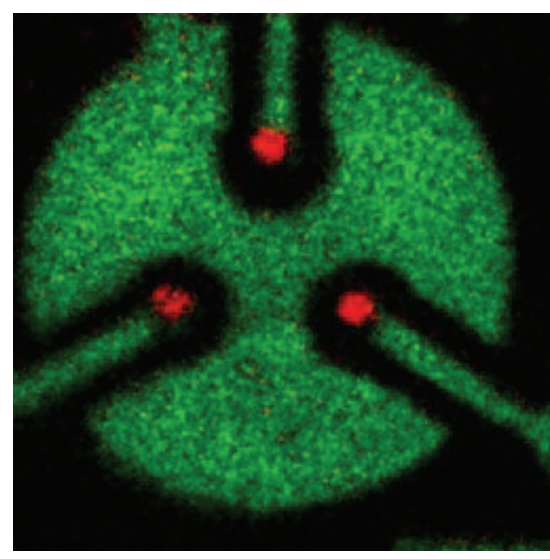

(b)

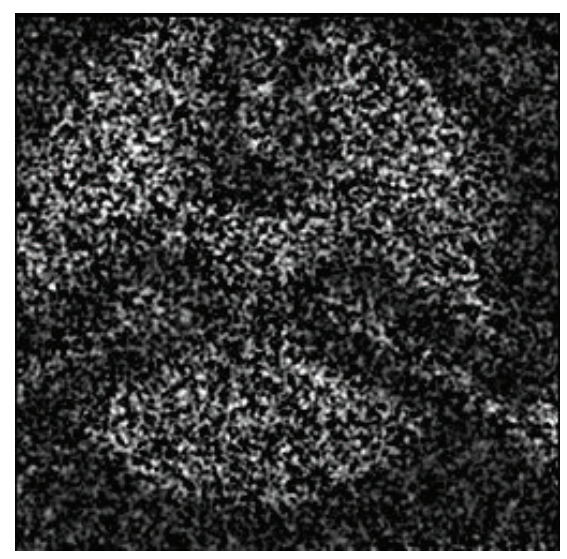

(c)

FIGURE 7: XPS mappings of the fixed base of DS switch: (a) Au 4f (XPS survey spectra were collected in marked points P1-P3 and P5), (b) Au $4 \mathrm{f}$ (green color) and Rh 3d (red color), and (c) $\mathrm{Cu} 2 \mathrm{p}$.

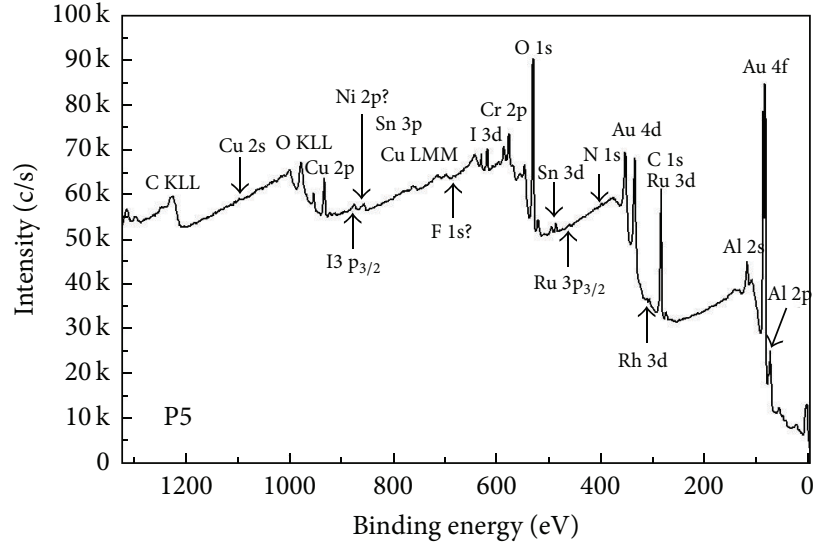

(a)

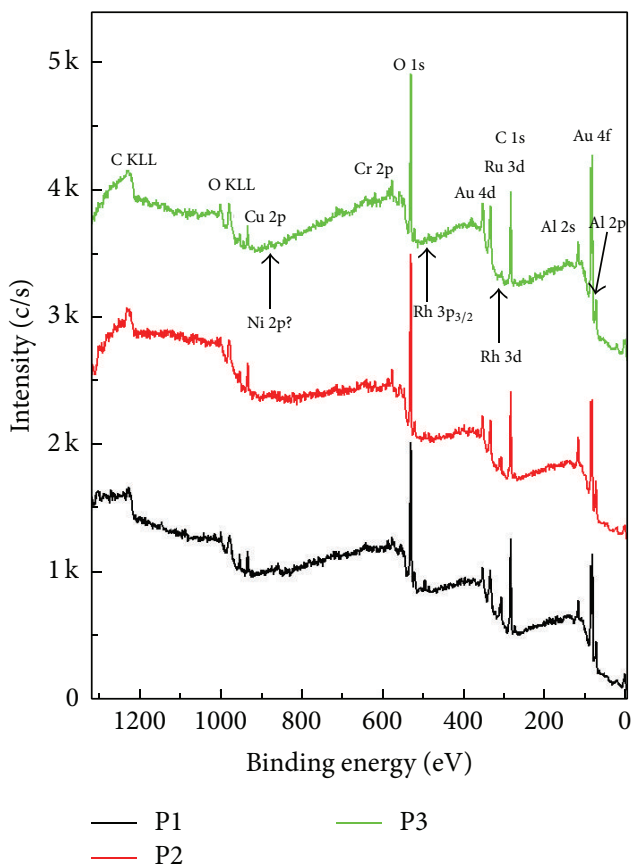

(b)

FIGURE 8: XPS spectra measured in point P5 (a) and points P1-P3 (b) shown in Figure 7(a).

Aluminum on the contacting surfaces of DS switch was found mainly in the form of alumina, and its concentration was approximately equal to $\mathrm{Rh}$ concentration. Besides, $\mathrm{Al}$ was observed not only on the contacting surfaces and on the conducting paths (Figure 2) but also on the outside of the movable cover (Figure 3). It means that the most probable source of $\mathrm{Al}$ contamination is microparticles of alumina appearing during mechanical treatment of a sapphire substrate. Figure 5 shows that an additional source of $\mathrm{Al}, \mathrm{Ca}$, and $\mathrm{Ti}$ contamination is electrolyte used for $\mathrm{Rh}$ plating. All these impurities along with $\mathrm{C}$ are deposited on the contacting surfaces and provoke the development of its porosity. Consequently, the resistivity of the defective switch became greater than that in the order of magnitude in comparison with the working switch.

\section{Conclusions}

The results of the present study provide a detailed characterization of the contacting surfaces of MEMS electrostatic switches. Microstructural features and elemental and chemical compositions including chemical mappings were measured by means of SEM, EDXA, and XPS. Our focus is on the difference between the data collected for the devices that 
had passed the electrical conductivity test $\left(R_{\mathrm{st}} \leq 0.15 \mathrm{Ohm}\right)$ and those found to be defective $\left(R_{\mathrm{st}}>0.15 \mathrm{Ohm}\right)$. It was shown that the contacting surfaces, conducting paths, and other parts of defective switches were contaminated by $\mathrm{C}, \mathrm{O}$, $\mathrm{Al}, \mathrm{Ca}, \mathrm{Ti}, \mathrm{Cu}$, and some other impurities. On the contrary, the details of working switches were found to be clean, at least at the level of EDXA and XPS sensitivity. The main sources of surface impurities and defects causing MEMS failure are as follows: (i) incompletely deleted sacrificial layers, (ii) substrate materials, and (iii) electrolytes employed for $\mathrm{Rh}$ plating of the contacts. The negative influence of foreign microparticles, especially alumina and copper oxides, on the conductivity and porosity of contacts was highlighted.

\section{Conflict of Interests}

The authors declare that there is no conflict of interests regarding the publication of this paper.

\section{Acknowledgments}

This work was supported by the Ryazan Metal Ceramics Instrumentation Plant Joint Stock Company, Special Engineering Design Bureau Joint Stock Company (Veliky Novgorod), and Portuguese Foundation for Science and Technology via the Project PTDC/CTM-ENE/2514/2012.

\section{References}

[1] J. Schimkat, "Contact measurements providing basic design data for microrelay actuators," Sensors and Actuators A: Physical, vol. 73, no. 1-2, pp. 138-143, 1999.

[2] S. M. Karabanov, I. A. Zeltser, R. M. Maizels, E. N. Moos, and K. A. Arushanov, "Creation of principally new generation of switching technique elements (reed switches) with nanostructured contact surfaces," Journal of Physics: Conference Series, vol. 291, no. 1, Article ID 012020, 2011.

[3] K. Arushanov, I. Zeltser, S. Karabanov et al., "Ion-induced surface modification of magnetically operated contacts," Coatings, vol. 2, no. 2, pp. 8-44, 2012.

[4] K. A. Arushanov, M. N. Drozdov, S. M. Karabanov, I. A. Zeltser, and A. Tolstogouzov, "TOF-SIMS study on surface modification of reed switch blades by pulsing nitrogen plasma," Applied Surface Science, vol. 265, pp. 642-647, 2013.

[5] I. A. Zeltser and R. A. Nekrasov, "Technological artefacts in the stage of sealing of reed switches," in Proceedings of the 1st International Scientific and Practical Conference on Magnetically Operated Contacts (Reed Switches) and Reed Switches Based Products (ICRS '05), pp. 56-65, Ryazan, Russia, October 2005, (Russian). 

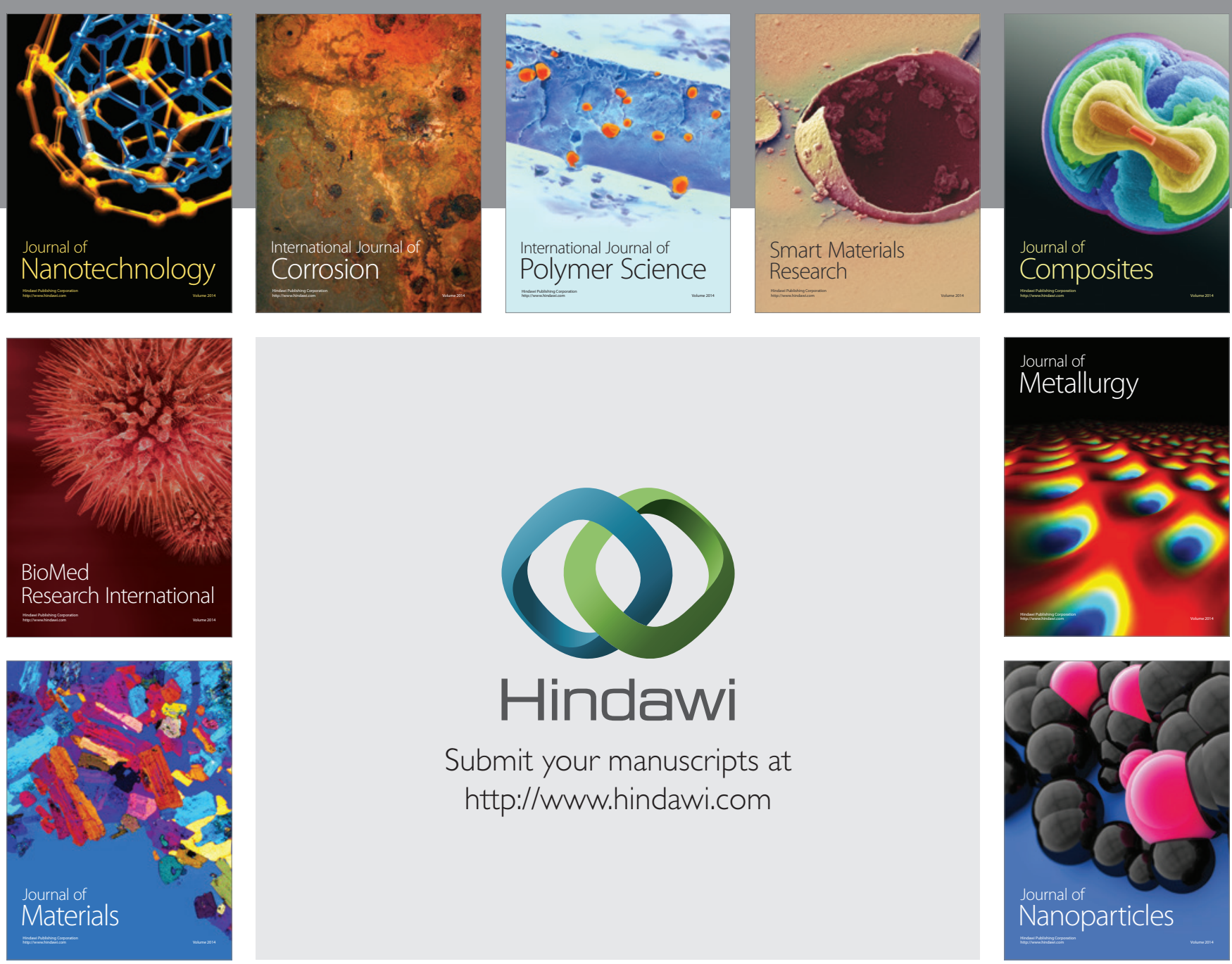

Submit your manuscripts at http://www.hindawi.com
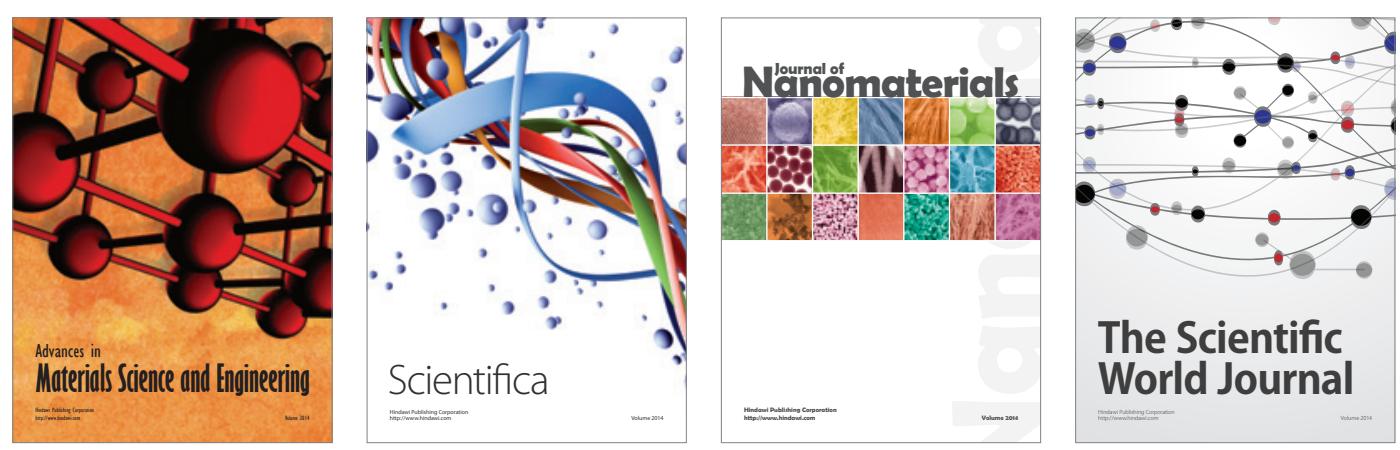

\section{The Scientific World Journal}
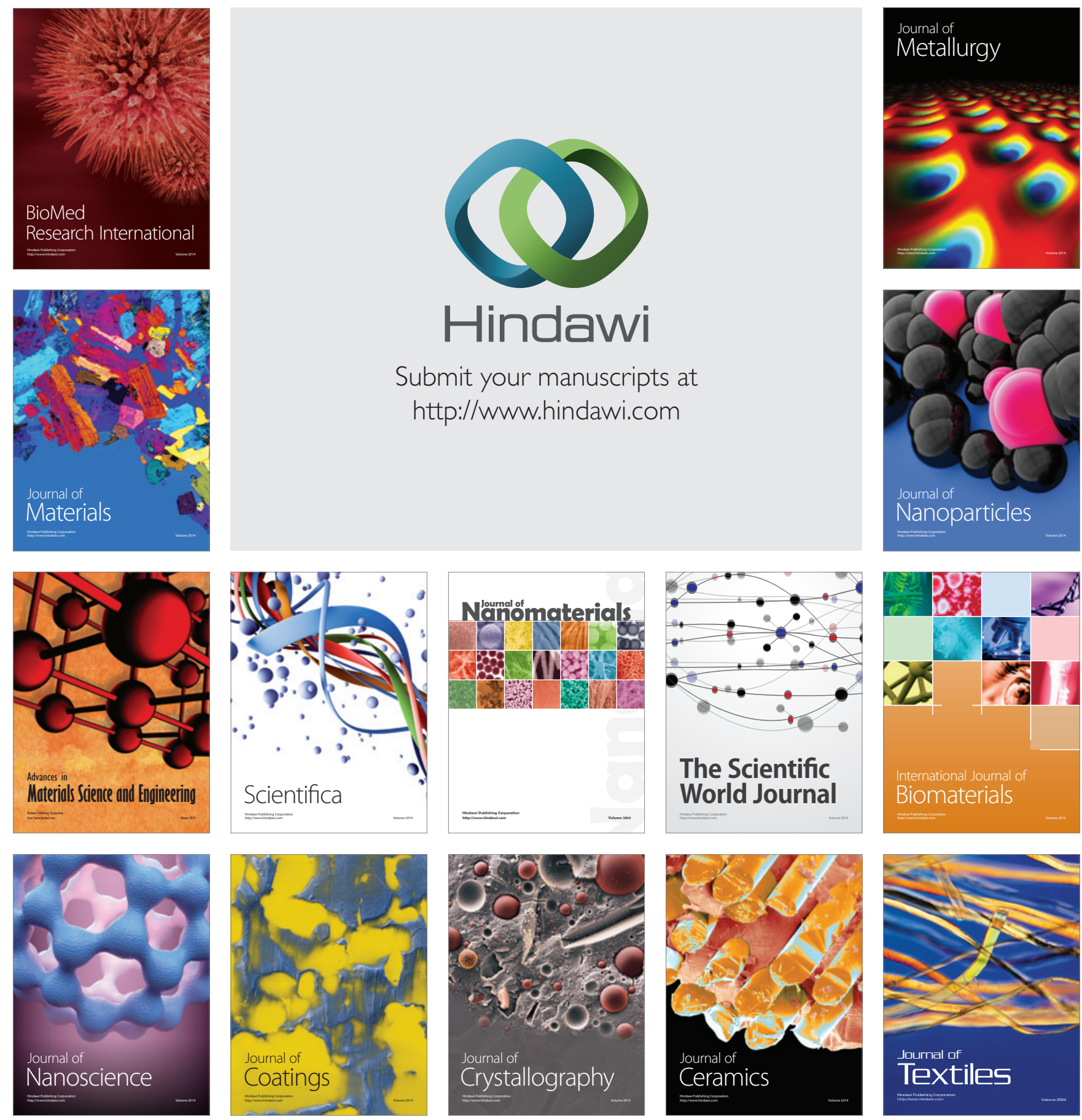